\title{
Synergistic Computational-experimental Discovery of Highly Selective PtCu Nanocluster Catalysts for Acetylene Semihydrogenation
}

\author{
Olumide Bolarinwa Ayodele, ${ }^{1}$ Rongsheng Cai, ${ }^{2}$ Jianguang Wang, ${ }^{3}$ Yasmine Ziouani, ${ }^{1}$ Zhifu Liang, ${ }^{4}$ M. \\ Chiara Spadaro, ${ }^{2,4}$ Kirill Kovnir,, ${ }^{5,6}$ Jordi Arbiol, ${ }^{4,7}$ Jaakko Akola, ${ }^{3,8, *}$ Richard E. Palmer, ${ }^{2, *}$ and Yury V. \\ Kolen'ko ${ }^{1, *}$ \\ ${ }^{1}$ Department of Micro and Nanofabrication, International Iberian Nanotechnology Laboratory, Braga 4715-330, Portugal \\ ${ }^{2}$ College of Engineering, Swansea University, Bay Campus, Fabian Way, Swansea SA1 8EN, United Kingdom \\ ${ }^{3}$ Computational Physics Laboratory, Tampere University, P.O. Box 692, Tampere 33014, Finland \\ ${ }^{4}$ Catalan Institute of Nanoscience and Nanotechnology (ICN2), CSIC and BIST, Campus UAB, Bellaterra, 08193 Barcelona, \\ Catalonia, Spain \\ ${ }^{5}$ Department of Chemistry, Iowa State University, Ames IA, 50011 USA \\ ${ }^{6}$ Ames Laboratory, U.S. Department of Energy, Ames IA, 50011 USA \\ ${ }^{7}$ ICREA, Pg. Lluís Companys 23, 08010 Barcelona, Catalonia, Spain \\ ${ }^{8}$ Department of Physics, Norwegian University of Science and Technology, Trondheim 7491, Norway
}

\begin{abstract}
Semihydrogenation of acetylene (SHA) in ethylene-rich stream is an important process for the polymer industries. Presently, Pd-based catalysts have demonstrated good acetylene conversion $\left(X_{\mathrm{C}_{2} \mathrm{H} 2}\right)$; however, at the expense of ethylene selectivity $\left(S_{\mathrm{C} 2 \mathrm{H} 4}\right)$. In this study, we have employed a systematic approach using density functional theory (DFT) to identify the best catalyst in a $\mathrm{Cu}-\mathrm{Pt}$ system. The DFT result showed that with a 55 atom system at $\sim 1.1 \mathrm{Pt} / \mathrm{Cu}$ ratio for $\mathrm{Pt}_{28} \mathrm{Cu}_{27} / \mathrm{Al}_{2} \mathrm{O}_{3}$, the $d$-band center shifted $-2.2 \mathrm{eV}$ relative to the Fermi level leading to electron-saturated Pt, which allows only adsorption of ethylene via a $\pi$ bond, resulting in theoretical $99.7 \% S_{\mathrm{C} 2 \mathrm{H} 4}$ at nearly complete $X_{\mathrm{C} 2 \mathrm{H} 2}$. Based on the DFT results, $\mathrm{Pt}-\mathrm{Cu} / \mathrm{Al}_{2} \mathrm{O}_{3}(\mathbf{P t C u})$ and $\mathrm{Pt} / \mathrm{Al}_{2} \mathrm{O}_{3}(\mathbf{P t})$ nanocatalysts were synthesized via cluster beam deposition (CBD) and their properties and activities were correlated with the computational predictions. For bimetallic PtCu, the electron microscopy results show the formation of alloys. The PtCu bimetallic catalyst closely mimics the DFT predictions both in terms of electronic structure, as confirmed by X-ray photoelectron spectroscopy, and catalytic activity. The alloying of $\mathrm{Pt}$ with $\mathrm{Cu}$ was responsible for the high $\mathrm{C}_{2} \mathrm{H}_{4}$ specific yield resulting from electron transfer between $\mathrm{Cu}$ and Pt, thus making PtCu a promising catalyst for SHA.
\end{abstract}

KEYWORDS: microkinetic model; hydrogenation; nanoclusters; alloys; cluster beam deposition.

Ethylene, $\mathrm{C}_{2} \mathrm{H}_{4}$, is an important feedstock in polymer industries and it also serves as an important intermediate in many industrial reactions. ${ }^{1}$ It is produced in large quantities via traditional thermal and catalytic cracking of naphtha and light hydrocarbons. In the course of its production, however, there is inadvertent production of small ca. $1 \%$ admixtures of acetylene, $\mathrm{C}_{2} \mathrm{H}_{2}$. Despite this low amount, acetylene poisons the olefin polyethylene Ziegler-Natta catalysts. Thus, the amount of $\mathrm{C}_{2} \mathrm{H}_{2}$ must be reduced to a level of a few ppm, as is currently researched and practiced using a hydrogenation process in either front-end and/or tail-end process configurations. ${ }^{2-3}$

Attaining high selectivity towards $\mathrm{C}_{2} \mathrm{H}_{4}\left(S_{\mathrm{C} 2 \mathrm{H} 4}\right)$ without further hydrogenation to ethane poses a serious challenge in acetylene semihydrogenation. ${ }^{4-5}$ According to the thermodynamic data, $\Delta H^{\circ}$ for hydrogenation of both $\mathrm{C}_{2} \mathrm{H}_{2}$ and $\mathrm{C}_{2} \mathrm{H}_{4}$ are quite similar (Eqs. 1-2). Thus, process conditions must be judiciously selected to avoid the thermodynamically favored subsequent $\mathrm{C}_{2} \mathrm{H}_{4}$ hydrogenation to ethane, $\mathrm{C}_{2} \mathrm{H}_{6}$, (Eq. 2).

$$
\begin{array}{ll}
\mathrm{C}_{2} \mathrm{H}_{2}+\mathrm{H}_{2} \rightarrow \mathrm{C}_{2} \mathrm{H}_{4} & \Delta H^{\circ}=-175.4 \mathrm{~kJ} \mathrm{~mol}^{-1} \\
\mathrm{C}_{2} \mathrm{H}_{4}+\mathrm{H}_{2} \rightarrow \mathrm{C}_{2} \mathrm{H}_{6} & \Delta H^{\circ}=-136.9 \mathrm{~kJ} \mathrm{~mol}^{-1}
\end{array}
$$

To achieve selective hydrogenation of $\mathrm{C}_{2} \mathrm{H}_{2}$ to $\mathrm{C}_{2} \mathrm{H}_{4}$, the appropriate interaction between the adsorbate and the catalytically active metal site must be established, as shown in the works of Hammer and Nørskov, ${ }^{6}$ satisfying the Sabatier principle; that is, having neither too strong nor too weak interaction. ${ }^{7}$ In this regard, a nearly linear relationship between the adsorption energy $\left(\Delta E_{\mathrm{ads}}\right)$ for a particular adsorbate and the metal surface $d$-band center has been established with the $\Delta E_{\text {ads }}$ becoming stronger when the active metal surface $d$-band center shifts closer to the Fermi level. ${ }^{8}$ This shift is considered largely due to the antibonding states created upon hybridization of the overlapping states above the Fermi level. Accordingly, when moving from left to right in the periodic table across the transition metals, the $d$-band becomes more filled and the $d$-band centre shifts away from the Fermi level. This explains why late transition platinum-group metals (PGMs) are being studied as potential candidates for $\mathrm{C}_{2} \mathrm{H}_{2}$ semihydrogenation.

In industrial processes, $\mathrm{Pd}$-based catalysts are used for selective semihydrogenation of $\mathrm{C}_{2} \mathrm{H}_{2}$. They provide good $\mathrm{C}_{2} \mathrm{H}_{2}$ conversion $\left(X_{\mathrm{C} 2 \mathrm{H} 2}\right)$, and are usually modified with ancillary metals, such as $\mathrm{Ag}, \mathrm{Au}, \mathrm{Cu}, \mathrm{Ga}$, and $\mathrm{Zn}$, to improve $S_{\mathrm{C} 2 \mathrm{H} 4 .}{ }^{9-10}$ 
For example, Pei et al. ${ }^{11}$ reported that the isolation of Pd atoms by Cu played a key role in enhancing $S_{\mathrm{C} 2 \mathrm{H} 4}$. Similarly, Liu et al. ${ }^{12}$ in a study using PdAg catalyst ascribed the preferred selectivity towards $\mathrm{C}_{2} \mathrm{H}_{4}$ to the electronic effect between the supporting material and the $\mathrm{PdAg}$ nanoalloys. In another study using trimetallic $\mathrm{PdAuAg}, \mathrm{PdAuAg}_{x}$, and bimetallic $\mathrm{PdAu}$ and PdAg catalysts, ${ }^{13}$ it was found that the trimetallic catalysts have superior $S_{\mathrm{C} 2 \mathrm{H} 4}$ compared to the bimetallic catalyst at high $X_{\mathrm{C} 2 \mathrm{H} 2}$ due to a positive synergetic effect. Mei et al. ${ }^{14}$ showed that the rate of $\mathrm{C}_{2} \mathrm{H}_{2}$ hydrogenation as well as $S_{\mathrm{C} 2 \mathrm{H} 4}$ increases with temperature over both the $\mathrm{Pd}(111)$ and the $\mathrm{Pd}-$ $\mathrm{Ag} / \mathrm{Pd}(111)$ alloy surfaces. These promising examples of alloy catalysts motivate us to conduct a theoretical and experimental investigation of the alloy nanoparticles in hope of developing new active and selective catalysts for $\mathrm{C}_{2} \mathrm{H}_{2}$ semihydrogenation.

In the current study, we focus on the $\mathrm{Pt}-\mathrm{Cu}$ alloy catalyst. The optimal size and composition of the catalyst are computationally guided, allowing to effectively isolate Pt active sites via alloying with $\mathrm{Cu}$ to favor high $S_{\mathrm{C} 2 \mathrm{H} 4}$ at high $X_{\mathrm{C} 2 \mathrm{H} 2}$. The density functional theory (DFT) model provides insights into the reaction mechanisms and adsorption energies at the catalyst surface, and correlate the high yield of $\mathrm{C}_{2} \mathrm{H}_{4}\left(\hat{Y}_{\mathrm{C} 2 \mathrm{H} 4}\right)$ with the $d$-band theory. Based on the predicted catalytic properties using microkinetic simulations, we employ cluster beam deposition (CBD) method to synthesize PtCu nanoclusters supported on $\mathrm{Al}_{2} \mathrm{O}_{3}$ and correlate its structural, textural, and morphological properties with the activities in selective hydrogenation of $\mathrm{C}_{2} \mathrm{H}_{2}$ to $\mathrm{C}_{2} \mathrm{H}_{4}$.

We start by building a $\mathrm{Pt}_{28} \mathrm{Cu}_{27}$ cluster model structure supported on alumina surface. Upon optimization, the $\mathrm{Pt}_{28} \mathrm{Cu}_{27}$ cluster maintains the icosahedron-like structure regardless of the cluster facet bonding to the oxide support. The lowestenergy structure of $\mathrm{Pt}_{28} \mathrm{Cu}_{27} / \mathrm{Al}_{2} \mathrm{O}_{3}(100)$ is given in Figure $\mathrm{S} 1 \mathrm{a}$ in the Supporting Information (SI), and the cluster adsorption energy $\Delta E_{\text {clus }}$ is calculated to be $6.32 \mathrm{eV}$. The optimized cluster diameter is around $10 \AA$ and the average bond distance $(\mathrm{Pt}-\mathrm{O}, \mathrm{Cu}-\mathrm{O})$ between the cluster and surface is $2.14 \AA$. The optimized bond lengths of $\mathrm{Pt}-\mathrm{Cu}$ (shell) and $\mathrm{Cu}-\mathrm{Cu}$ (core) are 2.64 and $2.54 \AA$, respectively. The average core-shell distance is $2.57 \AA$ (including $\mathrm{Pt}-\mathrm{Cu}$ and $\mathrm{Cu}-\mathrm{Cu}$ ). Bader charge analysis shows that the $\mathrm{Al}_{2} \mathrm{O}_{3}$ substrate transfers 0.71 e to $\mathrm{Pt}_{28} \mathrm{Cu}_{27}$, resulting in a slightly negatively charged catalyst. From the charge density difference visualization (Figure S1b), charge accumulation and depletion can be seen mostly at the interface between $\mathrm{Pt}_{28} \mathrm{Cu}_{27}$ and $\mathrm{Al}_{2} \mathrm{O}_{3}$. There is also accumulated charge density around the cluster perimeter indicating electron transfer to the cluster, which is in accord with the result of the Bader charge analysis.

The electronic structures of the projected density of states (PDOS) (Figure S1c) show the projection of Kohn-Sham single-particle states onto atomic $s-, p-, d$-, and $f$-components in the catalyst and support, respectively. At the Fermi level, the weight of PDOS is significant on the cluster $(\mathrm{Pt}-\mathrm{Cu} d$ orbitals), while the support (insulator) exhibits a bandgap. In addition, the $d$-band center with respect to the Fermi level is calculated to be $-2.20 \mathrm{eV}$ for the supported $\mathrm{Pt}_{28} \mathrm{Cu}_{27}$ cluster, comparable with the reported $d$-band center of $-2.07 \mathrm{eV}$ for the surface atoms of the $\mathrm{Pt}_{28} \mathrm{Cu}_{27}$ cluster. ${ }^{15}$ The highest occupied and lowest unoccupied molecular orbital (HOMO-LUMO) distributions (Figure S1d) show that the states relevant for chemical reactivity are mainly delocalized around $\mathrm{Pt}_{28} \mathrm{Cu}_{27}$, emphasizing the catalytic role of the cluster.
For the DFT simulations of acetylene hydrogenation over $\mathrm{Pt}_{28} \mathrm{Cu}_{27} / \mathrm{Al}_{2} \mathrm{O}_{3}(100)$, we assume first that hydrogen atoms become available on the catalyst surface from $\mathrm{H}_{2}$ molecule dissociation (Figure $\mathrm{S} 2$ and associated text). Next, based on the $\mathrm{H}^{*}+\mathrm{H}^{*}$ co-adsorption configuration, the adsorption sites for $\mathrm{C}_{2} \mathrm{H}_{2}$ and $\mathrm{C}_{2} \mathrm{H}_{4}$ were mapped individually on the cluster surface. The corresponding adsorption energy $\left(\Delta E_{a d s}\right)$ was calculated as

$\Delta E_{\text {ads }}=E[$ adsorbate $]+E\left[\mathrm{Pt}_{28} \mathrm{Cu}_{27}\left(\mathrm{H}_{2} / \mathrm{Al}_{2} \mathrm{O}_{3}\right]-E[\right.$ adsorbate $\left.+\mathrm{Pt}_{28} \mathrm{Cu}_{27}(\mathrm{H})_{2} / \mathrm{Al}_{2} \mathrm{O}_{3}\right]$

where $E(Y)$ is the total energy of the corresponding system Y. The calculated values are given in Table $\mathrm{S} 1$.
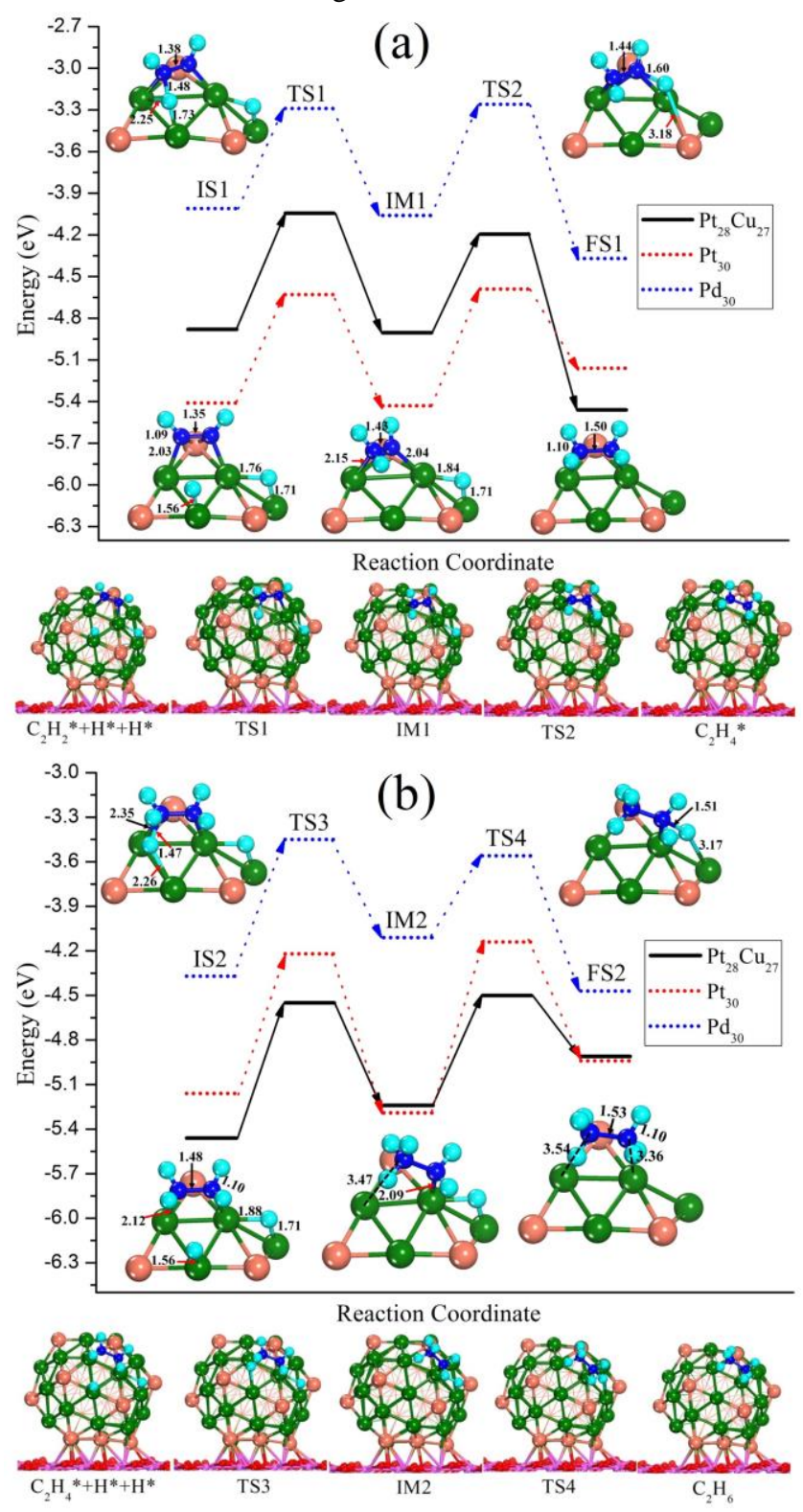

Figure 1. Structures of the IS, TS, IM, and FS, and the energy diagrams along the hydrogenation pathways of acetylene to ethylene $\left(\mathrm{C}_{2} \mathrm{H}_{2} *+\mathrm{H}^{*}+\mathrm{H}^{*} \rightarrow \mathrm{C}_{2} \mathrm{H}_{4} *\right)$ (a), and ethylene to ethane $\left(\mathrm{C}_{2} \mathrm{H}_{4} *+\mathrm{H}^{*}+\mathrm{H}^{*} \rightarrow \mathrm{C}_{2} \mathrm{H}_{6}\right)$ (b) over $\mathrm{Pt}_{28} \mathrm{Cu}_{27} / \mathrm{Al}_{2} \mathrm{O}_{3}$ catalyst. The zero-level of energy corresponds to the reactants $\left(\mathrm{C}_{2} \mathrm{H}_{2}\right.$ and $\left.2 \mathrm{H}_{2}\right)$ in the gas phase. The energy levels for $\mathrm{Pt}_{30} / \mathrm{Al}_{2} \mathrm{O}_{3}$ and $\mathrm{Pd}_{30} / \mathrm{Al}_{2} \mathrm{O}_{3}$ catalysts are given for reference. The geometrical parameters are given in $\AA$. The symbol * refers to an atom or molecule being adsorbed on the catalyst. Color key: $\mathrm{Pt}$, green; $\mathrm{Cu}$, coral; $\mathrm{H}$, aqua; $\mathrm{C}$, blue; $\mathrm{O}$, red; $\mathrm{Al}$, pink. 

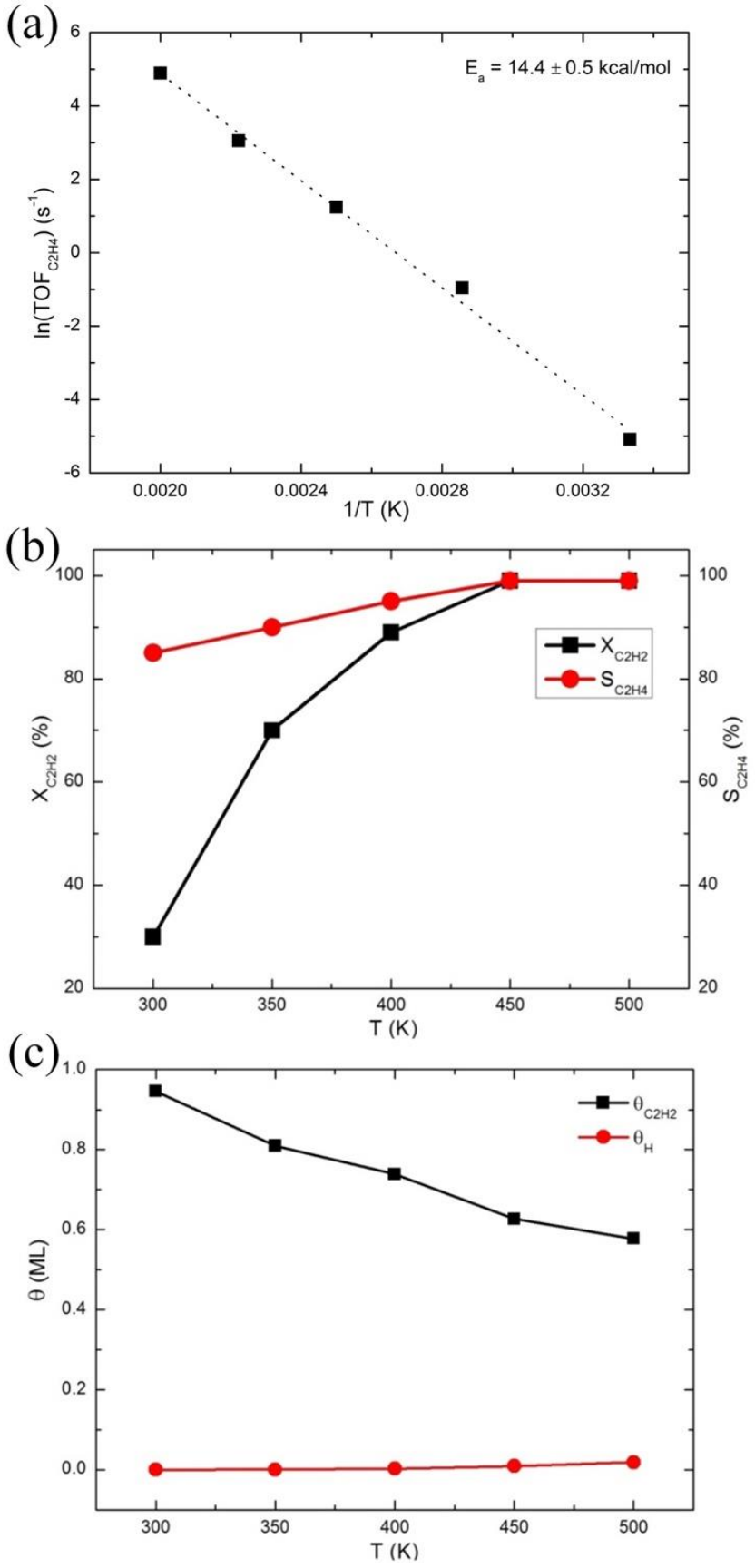

Figure 2. Microkinetic modeling results as a function of temperature in acetylene hydrogenation over $\mathrm{Pt}_{28} \mathrm{Cu}_{27} / \mathrm{Al}_{2} \mathrm{O}_{3}(100)$. (a) Arrhenius plot of $\mathrm{C}_{2} \mathrm{H}_{4}$ formation TOF, (b) $X_{\mathrm{C} 2 \mathrm{H} 2}$ and $S_{\mathrm{C} 2 \mathrm{H} 4}$, and (c) $\theta_{\mathrm{H}}$ and $\theta_{\mathrm{C} 2 \mathrm{H} 2}$. The simulations use atmospheric pressure and feed composition of $2 \% \mathrm{C}_{2} \mathrm{H}_{2}$ and $20 \% \mathrm{H}_{2}$.

The structures of the reaction initial state (IS), transition state (TS), intermediate state (IM), and final state (FS), and the energy diagrams along the acetylene hydrogenation pathways of $\mathrm{C}_{2} \mathrm{H}_{2} *+\mathrm{H}^{*}+\mathrm{H}^{*} \rightarrow \mathrm{C}_{2} \mathrm{H}_{4} *$ and $\mathrm{C}_{2} \mathrm{H}_{4} *+\mathrm{H}^{*}+\mathrm{H}^{*} \rightarrow \mathrm{C}_{2} \mathrm{H}_{6}$ are given in Figures $1 \mathrm{a}$ and $1 \mathrm{~b}$, respectively. The energy values are listed in Table S2 where the shift of the zero-level corresponds to co-adsorption of the reactants from the gas phase $\left(\mathrm{C}_{2} \mathrm{H}_{2}\right.$ and $\left.2 \mathrm{H}_{2}\right)$. At IS1, $\mathrm{C}_{2} \mathrm{H}_{2}$ binds to a hollow site composed by a $\mathrm{Pt}-\mathrm{Cu}-\mathrm{Pt}$ fragment on the cluster surface with $\Delta E_{\text {ads }}=2.40 \mathrm{eV}$. The catalyst transfers $0.30 e$ electron density to the adsorbed $\mathrm{C}_{2} \mathrm{H}_{2}$ molecule. In the process of $\mathrm{C}_{2} \mathrm{H}_{2}$ hydrogenation to $\mathrm{C}_{2} \mathrm{H}_{4}$ (FS1), two $\mathrm{H}^{*}$ atoms are added to $\mathrm{C}_{2} \mathrm{H}_{2}$ through TS1, IM1, and TS2 along the reaction pathway (Figure 1a). In TS1, the first $\mathrm{H}$ atom moves to the adjacent bridge site from its original top site with an activation energy of $0.83 \mathrm{eV}$, which is comparable with the reported value $0.90 \mathrm{eV}$ on $\mathrm{Pt}(111)$ surface. ${ }^{16} \mathrm{IM} 1$ corresponds to the $\mathrm{C}_{2} \mathrm{H}_{3}$ intermediate with a reaction energy of $-0.03 \mathrm{eV}$. The activation energy barrier for adding the second $\mathrm{H}$ atom (TS2) is $0.68 \mathrm{eV}$ $\left(0.69 \mathrm{eV}\right.$ for $\left.\mathrm{Pt}(111)^{16}\right)$ and the $\mathrm{C}_{2} \mathrm{H}_{4}$ product is then formed in FS1 with an exothermic reaction energy of $-0.56 \mathrm{eV}$.

For the second step reaction of $\mathrm{C}_{2} \mathrm{H}_{4} *+\mathrm{H}^{*}+\mathrm{H}^{*} \rightarrow \mathrm{C}_{2} \mathrm{H}_{6}$, $\mathrm{C}_{2} \mathrm{H}_{4}$ prefers to bind on a $\mathrm{Pt}-\mathrm{Pt}$ bridge site in the presence of the two $\mathrm{H}^{*}$ atoms with $\Delta E_{\text {ads }}=1.50 \mathrm{eV}$ and a net charge of 0.07e. Similarly as before, $\mathrm{C}_{2} \mathrm{H}_{4}$ is hydrogenated to $\mathrm{C}_{2} \mathrm{H}_{6}$ (FS2) by the two $\mathrm{H}^{*}$ atoms one-by-one. The reaction pathway in Figure $1 \mathrm{~b}$ to $\mathrm{C}_{2} \mathrm{H}_{6}$ includes two transition states with activation energy barriers of $0.91 \mathrm{eV}$ (TS3) $\left(1.18 \mathrm{eV}\right.$ for $\left.\mathrm{Pt}(111)^{16}\right)$ and $0.96 \mathrm{eV}$ (TS4) and one intermediate state (IM2, $\left.\mathrm{C}_{2} \mathrm{H}_{5}\right)$ with a positive reaction energy of $0.22 \mathrm{eV}$. Here, the higher activation energy barriers imply overall selectivity towards desired $\mathrm{C}_{2} \mathrm{H}_{4}$. Furthermore, the $\mathrm{C}_{2} \mathrm{H}_{6}$ final product (FS2) is generated with an endothermic reaction energy of $0.55 \mathrm{eV}$. The final adsorption energy of ethane $(0.36 \mathrm{eV}$, Table S3) indicates weak binding on the cluster surface, and it is reflected in the $\mathrm{C}-\mathrm{C}$ and $\mathrm{C}-\mathrm{H}$ bond lengths, which are within $0.01 \AA$ from the gas-phase values.

Here, we further compare the results with our DFT calculations of the same reactions on $\mathrm{Pd}_{30} / \mathrm{Al}_{2} \mathrm{O}_{3}(100)^{19}$ and $\mathrm{Pt}_{30} / \mathrm{Al}_{2} \mathrm{O}_{3}(100)$ catalysts. The reaction energy levels are shown in Figure 1 together with the $\mathrm{Pt}_{28} \mathrm{Cu}_{27}$ results by applying the reactant co-adsorption shift, and the reaction paths for $\mathrm{Pt}_{30}$ are shown in Figure S3. Overall, the reaction barrier heights (Table S2) are similar for the three cluster catalysts but there are noticeable differences in terms of reaction energetics. Firstly, $\mathrm{Pt}_{30}$ displays the largest adsorption energies for $\mathrm{C}_{2} \mathrm{H}_{2}$ and $\mathrm{C}_{2} \mathrm{H}_{4}$ (Table S3) indicating that the catalyst has a stronger tendency to get poisoned by acetylene and that the removal of ethylene requires more energy. Secondly, the $\mathrm{C}_{2} \mathrm{H}_{4} \rightarrow \mathrm{C}_{2} \mathrm{H}_{6}$ reaction profile goes uphill for $\mathrm{Pt}_{28} \mathrm{Cu}_{27}$ with a final state that is $0.55 \mathrm{eV}$ higher than IS2 meaning that the reaction can flow backwards towards ethylene more easily than those for $\mathrm{Pt}_{30}$ and $\mathrm{Pd}_{30}$. It should be noted here that there is an energy level cross-over between $\mathrm{Pt}_{30}$ and $\mathrm{Pt}_{28} \mathrm{Cu}_{27}$ at $\mathrm{FS} 1$ although the former has a larger ethylene adsorption energy. This is due to the non-optimal final $\mathrm{C}_{2} \mathrm{H}_{4}$ adsorption site on $\mathrm{Pt}_{30}$, and the same is observed for $\mathrm{Pd}_{30}$ also. In case $\mathrm{C}_{2} \mathrm{H}_{4}$ is allowed to diffuse to a lower energy site, the FS1 energies of $\mathrm{Pt}_{30}$ and $\mathrm{Pd}_{30}$ will reduce correspondingly, but this will also result in additional steps (barriers involved) within the reaction scheme. Based on these reaction paths, the DFT results suggest that $\mathrm{Pt}_{28} \mathrm{Cu}_{27}$ is a more promising catalyst for SHA than $\mathrm{Pt}_{30}$ (adsorption + energetics), while the same cannot be concluded for $\mathrm{Pd}_{30}$ which has smaller molecular adsorption energies overall but does not display the same endothermic behavior upon the subsequent ethylene hydrogenation reaction (selectivity).

After conducting DFT studies of the surface-supported bimetallic cluster energetics, $\mathrm{H}_{2}$ dissociation, and favorable $\mathrm{C}_{2} \mathrm{H}_{2}$ hydrogenation pathways, we move forward with microkinetic modeling to virtually assess the catalytic performance of this promising system. Figure 2 displays the microkinetic modeling results for the temperature dependence of Arrhenius plot of ethylene formation turnover frequency (TOF) (a), $X_{\mathrm{C}_{2} \mathrm{H} 2}$ and $S_{\mathrm{C} 2 \mathrm{H} 4}(\mathrm{~b})$, and surface coverages of $\mathrm{H}\left(\theta_{\mathrm{H}}\right)$ and $\mathrm{C}_{2} \mathrm{H}_{2}\left(\theta_{\mathrm{C} 2 \mathrm{H} 2}\right)$ species (c). The simulation indicates that the TOF of desired $\mathrm{C}_{2} \mathrm{H}_{4}$ increases with temperature. The apparent activation energy $\left(E_{a}\right)$ is found to be $14.4 \pm 0.5 \mathrm{kcal} \mathrm{mol}^{-1}$ by fitting the 
Arrhenius plot in Figure 2a, comparable with the experimental values for the $\mathrm{Pt}$ catalysts ranging from 9.56 to $16.7 \mathrm{kcal} \mathrm{mol}^{-1} \cdot \cdot^{17-18}$ In addition, the rationality of the simulated $E_{\mathrm{a}}$ has been verified for $\mathrm{Pd}_{30}$ in our recent study, ${ }^{19}$ where the estimated value of $8.8 \mathrm{kcal} \mathrm{mol}^{-1}$ is comparable with the experimental one of $9.6 \mathrm{kcal} \mathrm{mol}{ }^{-1} \cdot{ }^{20}$ It should be noted that this apparent activation energy is a resulting quantity from the microkinetic model, and it does not directly correspond to the DFT-calculated activation barriers in the elementary reaction steps as shown in Figure 1.

In Figure 2b, one can see that $X_{\mathrm{C} 2 \mathrm{H} 2}$ and $S_{\mathrm{C} 2 \mathrm{H} 4}$ increase with the temperature: $X_{\mathrm{C} 2 \mathrm{H} 2}$ increases from $85 \%$ at $300 \mathrm{~K}$ to $100 \%$ at $450 \mathrm{~K}$, and $S_{\mathrm{C} 2 \mathrm{H} 4}$ increases from $30 \%$ at $300 \mathrm{~K}$ to $100 \%$ at $450 \mathrm{~K}$. Notably, the formation of $\mathrm{C}_{4}$ and $\mathrm{C}_{6}$ byproducts as well as presence of $\mathrm{C}_{2} \mathrm{H}_{4}$ in feed stream are not included in our model, which can lower the ethylene selectivity at lowtemperature experiments. ${ }^{20}$ The surface coverages for all species were also examined, and the results for $\theta_{\mathrm{H}}$ and $\theta_{\mathrm{C} 2 \mathrm{H} 2}$ are plotted in Figure $2 \mathrm{c}$ as a function of temperature. They exhibit different behavior with increasing temperature, namely, while $\theta_{\mathrm{C} 2 \mathrm{H} 2}$ decreases from 0.94 to 0.57 monolayer from 300 to $500 \mathrm{~K}, \theta_{\mathrm{H}}$ slowly increases from 0 to 0.02 monolayer. The surface coverages of the other species (vinyl, ethylene, ethyl, and ethane) are very low in the temperature range considered herein.
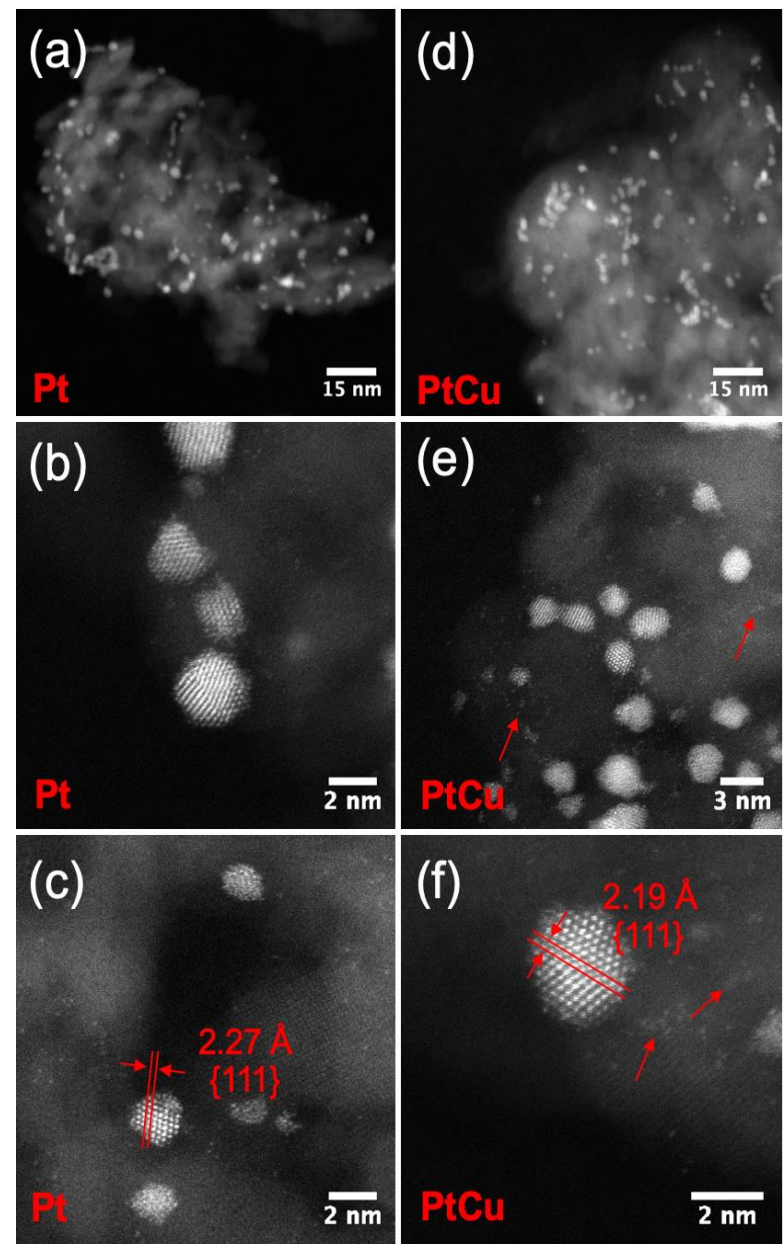

Figure 3 Representative low-magnification (a, d) and highresolution (b, c, e, and f) Atomic resolution HAADF-STEM images for control Pt and bimetallic PtCu cluster catalysts supported on $\mathrm{Al}_{2} \mathrm{O}_{3}$. The cluster interplanar spacing is indicated by two parallel lines. The red arrows indicate some small clusters or single atoms, which are mainly due to oxidation by air.
Based on the suggested high performance in terms of $X_{\mathrm{C} 2 \mathrm{H} 2}$ and $S_{\mathrm{C} 2 \mathrm{H} 4}$ of the $\mathrm{Pt}_{28} \mathrm{Cu}_{27} / \mathrm{Al}_{2} \mathrm{O}_{3}(100)$ model catalyst, a PtCu cluster catalyst $(\mathrm{Pt} / \mathrm{Cu}$ atomic ratio $\approx 1.1: 1)$ supported on $\mathrm{Al}_{2} \mathrm{O}_{3}$ was synthesized by CBD method to realize the model's prediction (Tables S4-S5). Additionally, monometallic Pt supported on $\mathrm{Al}_{2} \mathrm{O}_{3}$ was also prepared as a control cluster catalyst to understand the role of alloying (Tables S4-S5). Representative high-angle annular dark-field scanning transmission electron microscopy (HAADF-STEM) images for the Pt and $\mathbf{P t C u}$ cluster catalysts supported on $\mathrm{Al}_{2} \mathrm{O}_{3}$ powders are shown in Figure 3, while the estimated particle size distribution is presented in Figure S4. As one can see, most of the Pt clusters have a well-defined crystalline structure with a spheroidal shape. The interplanar spacing was measured to be $\approx 2.27 \AA$, which corresponds to the $\{111\}$ planes of Pt. For bimetallic $\mathbf{P t C u}$, in addition to larger crystalline PtCu clusters, smaller clusters or single atoms were observed. This is most likely due to oxidation in air, which can drive $\mathrm{Cu}$ atoms to the cluster surface and render the clusters easy to decompose, as shown previously elsewhere. ${ }^{21}$ The interplanar spacings of $\{111\}$ crystal planes $(2.19 \AA)$ measured from $\mathbf{P t C u}$ clusters were found to be slightly less than those of pure Pt $(2.265 \AA)$, suggesting that the CBD-produced $\mathbf{P t C u}$ clusters have an alloy structure following Vegard's law. ${ }^{22}$

To investigate the distribution of $\mathrm{Pt}$ and $\mathrm{Cu}$ elements within individual clusters, electron energy loss spectroscopy in STEM mode (STEM-EELS) chemical composition maps were obtained from the bimetallic PtCu catalyst (Figure 4). The $\mathrm{Pt}$ and $\mathrm{Cu}$ signals are well mixed together over the clusters, indicating the formation of $\mathrm{Pt}-\mathrm{Cu}$ alloy structure. This conclusion was further confirmed by the energy-dispersive $\mathrm{X}$ ray spectroscopy mapping results in STEM mode (STEMEDX) (Figure S5).

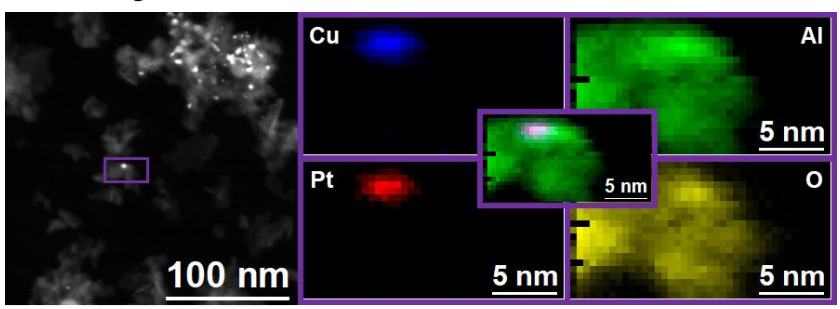

Figure 4. STEM-EELS chemical composition maps for bimetallic PtCu catalyst obtained on the purple area in the HAADFSTEM image (left). Individual $\mathrm{Cu} L_{2,3}$-edges at $931 \mathrm{eV}$ (blue), $\mathrm{Pt} M_{4,5}$-edges at $2122 \mathrm{eV}$ (red), $\mathrm{Al} K$-edge at $1560 \mathrm{eV}$ (green), and $\mathrm{O} K$-edge at $532 \mathrm{eV}$ (yellow), as well as their mixture in the center.

The results of catalytic activity of bimetallic $\mathbf{P t C u}$ and control Pt cluster catalysts prepared by CBD are summarized in Figure 5. $X_{\mathrm{C} 2 \mathrm{H} 2}$ of the Pt catalyst is quite high, indicating its high hydrogenation activity. Unfortunately, this catalyst exhibits full hydrogenation, thus increasing its selectivity to $\mathrm{C}_{2} \mathrm{H}_{6}$ $\left(S_{\mathrm{C} 2 \mathrm{H} 6}\right)$ at the expense of $S_{\mathrm{C} 2 \mathrm{H} 4}$, consequently depleting the $\mathrm{C}_{2} \mathrm{H}_{4}$ in the feed stream. The observed depletion of $\mathrm{C}_{2} \mathrm{H}_{4}$ in feed stream leading to negative $S_{\mathrm{C} 2 \mathrm{H} 4}$ is very common in the literature while using pure platinum group metal catalysts for this reaction. ${ }^{11,23}$ There was no formation of $\mathrm{C}_{4}$ by-products over the $\mathbf{P t}$ catalyst, which is consistent with the previous report for $\mathrm{Pd} / \mathrm{Cu}$ catalysts, wherein the $\mathrm{C}_{4}$ selectivity $\left(S_{\mathrm{C} 4}\right)$ decreased with increasing $\mathrm{Pd} / \mathrm{Cu}$ ratio. ${ }^{24}$ When $\mathrm{Pt}$ was alloyed with $\mathrm{Cu}$, there were marginal changes in $X_{\mathrm{C} 2 \mathrm{H} 2}$ as compared to the pure $\mathbf{P t}$ catalyst, but the overall efficiency was improved based on the $\mathrm{C}_{2} \mathrm{H}_{4}$ yield $\left(\hat{Y}_{\mathrm{C} 2 \mathrm{H} 4}\right)$ over bimetallic $\mathbf{P t C u}$ catalysts. 
Notably, PtCu catalyst synthesized to mimic the $\mathrm{Pt}_{28} \mathrm{Cu}_{27} / \mathrm{Al}_{2} \mathrm{O}_{3}(100)$ theoretical model exhibited the high catalytic performance activity based on $\hat{Y}_{\mathrm{C} 2 \mathrm{H} 4}$, and therefore it was important to understand its response to different reaction temperatures and $\mathrm{H}_{2}$ flowrates, since both parameters strongly affect reaction rates and equilibrium. As the reaction temperature was ramped up from 150 to $170^{\circ} \mathrm{C}, X_{\mathrm{C} 2 \mathrm{H} 2}$ increased by $\approx 20 \%$ without significant variations in $S_{\mathrm{C} 2 \mathrm{H} 4}$ and $S_{\mathrm{C} 2 \mathrm{H} 6}$ (Figure S6). Further increase in the reaction temperature to $200^{\circ} \mathrm{C}$ increased $X_{\mathrm{C} 2 \mathrm{H} 2}$ to $\approx 91 \%$ but at the expense of $S_{\mathrm{C} 2 \mathrm{H} 4}$, leading to an increase in $S_{\mathrm{C} 2 \mathrm{H} 6}$, which can be explained by the $\Delta H$ values in Eqs. 1-2. When the $\mathrm{H}_{2}$ flowrate was reduced irrespective of reaction temperature, both $X_{\mathrm{C} 2 \mathrm{H} 2}$ and $S_{\mathrm{C} 2 \mathrm{H} 6}$ reduced due to equilibrium constraints and insufficient $\mathrm{H}_{2}$ to further hydrogenate $\mathrm{C}_{2} \mathrm{H}_{4} \rightarrow \mathrm{C}_{2} \mathrm{H}_{6}$, thus leading to increased $S_{\mathrm{C} 2 \mathrm{H} 4}$.

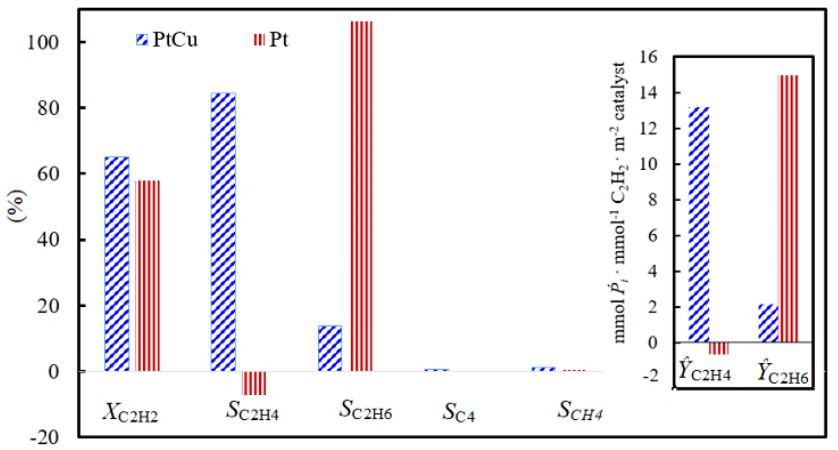

Figure 5. Catalytic properties of bimetallic PtCu and control Pt cluster catalysts in $\mathrm{C}_{2} \mathrm{H}_{2}$ semihydrogenation $\left(M_{\mathrm{CAT}}=20 \mathrm{mg}\right.$,

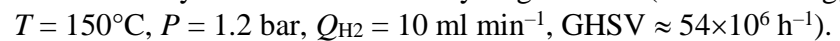

We report catalytic data that corroborates the theoretical suggestions. Specifically, we have found significantly increased $S_{\mathrm{C} 2 \mathrm{H} 4}$ at high $X_{\mathrm{C} 2 \mathrm{H} 2}$ for bimetallic PtCu cluster catalyst in comparison with the control Pt cluster catalyst. We further decided to rationalize this trend. A negative shift of the $d$-band center away from Fermi level resulted in weaker $\mathrm{C}_{2} \mathrm{H}_{4}$ adsorption due to $\pi$-type bonding. ${ }^{11,25}$ This holds true for many systems and reactions, but there are also reports where significant discrepancies were found, even when the $d$-band width and $s p$ electrons were considered. ${ }^{26-27}$ Thus, the upper $d$-band edge, $\varepsilon_{\mathrm{u}}$, defined as the highest peak position of the Hilbert transform of the PDOS onto $d$-orbitals of an active metal site, is identified as an electronic descriptor for the surface reactivity of transition metals and their alloys, irrespective of the variations in the $d$-band shape. ${ }^{26}$ The $\varepsilon_{\mathrm{u}}$ of $-0.11 \mathrm{eV}$ in Figure $6 \mathrm{a}$ is in agreement with $-0.12 \mathrm{eV}$ value reported for Pd-rich $\mathrm{Pd}_{3} \mathrm{Ir}$ alloy, supporting PtCu alloying resulting in weakened $\mathrm{C}_{2} \mathrm{H}_{4}$ adsorption on the catalyst surface. To experimentally validate the electronic structure of catalytic systems we conducted XPS analysis on bimetallic PtCu and benchmarked the result with control Pt (Figure 6b).

The XPS showed that in PtCu there is a slight shift in the Pt $4 \mathrm{~d}_{3 / 2}$ binding energy (BE) by $+0.28 \mathrm{eV}$ relative to Pt. Similar result was demonstrated by Fan et al. ${ }^{28}$ in the synthesis of $\mathrm{PdCu}$ alloy catalyst for modulating $d$-band electrons in methanol oxidation, where a marginal Pd $4 \mathrm{~d}_{5 / 2}$ BE shift of $+0.25 \mathrm{eV}$ was observed. The shift of $+0.28 \mathrm{eV}$ in $\mathrm{Pt} 4 \mathrm{~d}_{3 / 2}$ implies that there is electron transfer from $\mathrm{Cu}$ to $\mathrm{Pt}$ resulting in negatively charged Pt atoms, consistent with the metals' relative electronegativity and the PDOS plot in Figure S1c. Therefore, it is logical to expect that the higher electron density of Pt atoms within the PtCu prevents strong bonding of $\mathrm{C}_{2} \mathrm{H}_{4}$, most likely forming only weak $\pi$-bonded $\mathrm{C}_{2} \mathrm{H}_{4}$ that desorbs before enter- ing into undesired consecutive hydrogenation to $\mathrm{C}_{2} \mathrm{H}_{6}$. More so that it has been shown that alloying $\mathrm{Pt}$ with $\mathrm{Cu}$ resulted in $d$-band broadening induced by the lattice compression thus reducing the binding energy to the reactive intermediates, in this case, $\mathrm{C}_{2} \mathrm{H}_{4}$, thereby improving the performance. ${ }^{29}$ Hence, the PtCu exhibits very good selectivity to $\mathrm{C}_{2} \mathrm{H}_{4}$. Similar report ${ }^{11}$ on $\mathrm{Cu}$-alloyed Pd catalyst also demonstrated that only weakly $\pi$-bonded $\mathrm{C}_{2} \mathrm{H}_{4}$ species existed over the $\mathrm{PdCu}$ alloy catalyst, and the EXAFS results showed that the Pd atoms were completely isolated by $\mathrm{Cu}$.
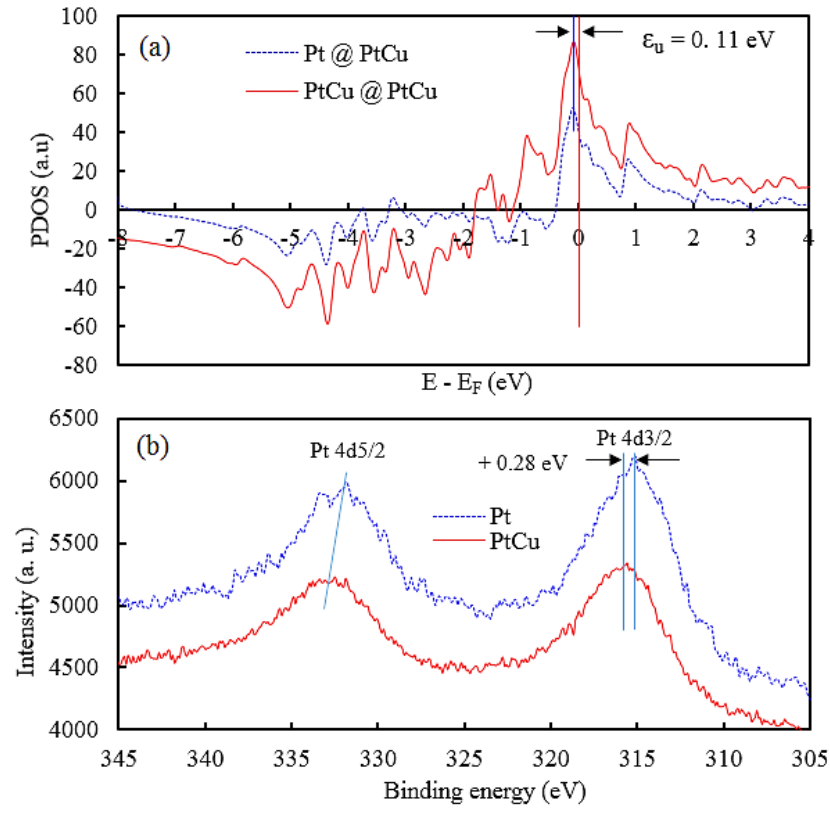

Figure 6. (a) The Hilbert transform of the local d-DOS of surface $\mathrm{Pt}$ atoms in $\mathrm{Pt}_{28} \mathrm{Cu}_{27} / \mathrm{Al}_{2} \mathrm{O}_{3}(100)$ alloy. The upper $d$-band edge $\varepsilon_{\mathrm{u}}$, defined as the highest peak position of the Hilbert transform of the local d-DOS, is marked with arrows. (b) XPS spectra of Pt 4d region showing $\mathrm{Pt} 4 \mathrm{~d}_{3 / 2}$ BE peak of $\mathbf{P t C u}$ shifted to higher BE by $0.28 \mathrm{eV}$ relative to $\mathbf{P t}$.

In conclusion, we have employed DFT-based microkinetic simulations to study $\mathrm{Pt}_{28} \mathrm{Cu}_{27} / \mathrm{Al}_{2} \mathrm{O}_{3}(100)$ cluster catalyst in semihydrogenation of $\mathrm{C}_{2} \mathrm{H}_{2}$ to $\mathrm{C}_{2} \mathrm{H}_{4}$. The findings show that this catalyst is a promising candidate for the reaction, and also a guided for further experimental research. To match the cluster sizes in DFT calculations, the catalysts were synthesized using cluster beam deposition method to achieve a narrow range of ultra-small nanoclusters. The experimental mimic of the theoretical $\mathrm{Pt}_{28} \mathrm{Cu}_{27}$ cluster, namely, bimetallic $\mathrm{PtCu}$ cluster catalyst showed high selectivity towards ethylene $\approx 85 \%$ and specific ethylene yield of $13.2 \mathrm{mmol} \mathrm{C}_{2} \mathrm{H}_{4} \mathrm{mmol}^{-}$ ${ }^{1} \mathrm{C}_{2} \mathrm{H}_{2} \mathrm{~m}^{-2}$ catalyst. According to the DFT studies, as corroborated by $\mathrm{X}$-ray photoelectron spectroscopy, alloying Pt metals with $\mathrm{Cu}$ weakens the $\mathrm{C}_{2} \mathrm{H}_{4}$ adsorption over the $\mathrm{Pt}$ active site by shifting the $d$-band center to $-2.2 \mathrm{eV}$ relative to Fermi level, which increases the electron density around the Pt atoms. Our results reveal that the alloying of platinum group metals with transition metals not only reduces the usage of rare and expensive elements but also significantly enhances the catalyst performance, especially in terms of selectivity.

\section{AUTHOR INFORMATION}

\section{Corresponding Author}

*E-mail: jaakko.akola@ntnu.no

*E-mail: r.e.palmer@swansea.ac.uk

*E-mail: yury.kolenko@inl.int 


\section{Notes}

The authors declare no competing financial interest.

\section{ASSOCIATED CONTENT}

The Supporting Information is available free of charge on the ACS Publications website. Materials and methods, additional computational, electron microscopy, textural property, and catalytic data (PDF).

\section{ACKNOWLEDGMENT}

We thank all members of the Nanochemistry Research Group at the INL for their fruitful scientific and technical input. This work was supported by the European Union's Horizon 2020 research and innovation program through the CritCat Project under Grant Agreement No. 686053. ICN2 acknowledges funding from Generalitat de Catalunya 2017 SGR 327 and the Spanish MINECO project ENE2017-85087-C3. ICN2 is supported by the Severo Ochoa program from Spanish MINECO (Grant No. SEV-20170706) and is funded by the CERCA Programme / Generalitat de Catalunya. Part of the present work has been performed in the framework of Universitat Autònoma de Barcelona Materials Science Ph.D. program. ZL acknowledges funding from MINECO SO FPI Ph.D. grant (SEV-2013-0295-17-1). MCS received funding from the European Union's Horizon 2020 research and innovation programme under the Marie SklodowskaCurie grant agreement No 754510 (PROBIST).

\section{REFERENCES}

1. Kim, S. K.; Lee, J. H.; Ahn, I. Y.; Kim, W.-J.; Moon, S. H. Performance of Cu-promoted Pd Ccatalysts Prepared by Adding $\mathrm{Cu}$ Using a Surface Redox Method in Acetylene Hydrogenation. Appl. Catal., A 2011, 401, 12-19.

2.Schbib, N. S.; García, M. A.; Gígola, C. E.; Errazu, A. F. Kinetics of Front-End Acetylene Hydrogenation in Ethylene Production. Ind. Eng. Chem. Res. 1996, 35, 1496-1505.

3.Kang, J. H.; Shin, E. W.; Kim, W. J.; Park, J. D.; Moon, S. H. Selective Hydrogenation of Acetylene on $\mathrm{TiO}_{2}$-Added $\mathrm{Pd}$ Catalysts. J. Catal. 2002, 208, 310-320.

4. Moses, J. M.; Weiss, A. H.; Matusek, K.; Guczi, L. The Effect of Catalyst Treatment on the Selective Hydrogenation of Acetylene over Aalladium/Alumina. J. Catal. 1984, 86, 417-426. 5. Armbrüster, M.; Kovnir, K.; Behrens, M.; Teschner, D.; Grin, Y.; Schlögl, R. Pd-Ga Intermetallic Compounds as Highly Selective Semihydrogenation Catalysts. J. Am. Chem. Soc. 2010, 132, 14745-14747.

6. Hammer, B.; Nørskov, J. K. Theoretical Surface Science and Catalysis-Calculations and Concepts. Adv. Catal. 2000, 45, 71129.

7. Cheng, J.; Hu, P. Utilization of the Three-Dimensional Volcano Surface To Understand the Chemistry of Multiphase Systems in Heterogeneous Catalysis. J. Am. Chem. Soc. 2008, 130, 1086810869 .

8. Guczi, L.; Molnár, Á.; Teschner, D. Hydrogenation Reactions: Concepts and Practice. In Comprehensive Inorganic Chemistry II 2nd ed: From Elements to Applications; Poeppelmeier, K., Ed.; Elsevier: Amsterdam, 2013; pp 421-457.

9. Kandaskalov, D.; Fournée, V.; Ledieu, J.; Gaudry, É. Catalytic Semihydrogenation of Acetylene on the (100) Surface of the o$\mathrm{Al}_{13 \mathrm{Co}} \mathrm{C}$ Quasicrystalline Approximant: Density Functional Theory Study. J. Phys. Chem. C 2017, 121, 18738-18745.

10. Kyriakou, G.; Boucher, M. B.; Jewell, A. D.; Lewis, E. A.; Lawton, T. J.; Baber, A. E.; Tierney, H. L.; FlytzaniStephanopoulos, M.; Sykes, E. C. H. Isolated Metal Atom Geometries as a Strategy for Selective Heterogeneous Hydrogenations. Science 2012, 335, 1209-1212.

11. Pei, G. X.; Liu, X. Y.; Yang, X.; Zhang, L.; Wang, A.; Li, L.; Wang, H.; Wang, X.; Zhang, T. Performance of Cu-Alloyed Pd
Single-Atom Catalyst for Semihydrogenation of Acetylene under Simulated Front-End Conditions. ACS Catal. 2017, 7, 1491-1500. 12. Liu, Y. N.; Feng, J. T.; He, Y. F.; Sun, J. H.; Li, D. Q. Partial Hydrogenation of Acetylene over a NiTi-layered Double Hydroxide Supported PdAg Catalyst. Catal. Sci. Technol. 2015, 5, 1231-1240.

13. Feng, J.; Liu, Y.; Yin, M.; He, Y.; Zhao, J.; Sun, J.; Li, D. Preparation and Structure-property Relationships of Supported Trimetallic PdAuAg Catalysts for the Selective Hydrogenation of Acetylene. J. Catal. 2016, 344, 854-864.

14. Mei, D.; Neurock, M.; Smith, C. M. Hydrogenation of Acetylene-ethylene Mixtures over $\mathrm{Pd}$ and $\mathrm{Pd}-\mathrm{Ag}$ Alloys: Firstprinciples-based Kinetic Monte Carlo Simulations. J. Catal. 2009, 268, 181-195.

15. Guedes-Sobrinho, D.; Nomiyama, R. K.; Chaves, A. S.; Piotrowski, M. J.; Da Silva, J. L. F. Structure, Electronic, and Magnetic Properties of Binary $\mathrm{Pt}_{n} \mathrm{TM}_{55-n}(\mathrm{TM}=\mathrm{Fe}, \mathrm{Co}, \mathrm{Ni}, \mathrm{Cu}$, Zn) Nanoclusters: A Density Functional Theory Investigation. $J$. Phys. Chem. C 2015, 119, 15669-15679.

16. Podkolzin, S. G.; Alcalá, R.; Dumesic, J. A. Density Functional Theory Studies of Acetylene Hydrogenation on Clean, Vinylidene- and Ethylidyne-covered Pt(111) Surfaces. J. Mol. Catal. A: Chem. 2004, 218, 217-227.

17. Advances in Catalysis and Related Subjects. In Index to Reviews, Symposia Volumes and Monographs in Organic Chemistry; Kharasch, N., Wolf, W., Eds.; Pergamon: Oxford, 1966; p 4.

18. Webb, G. Chapter 1 Catalytic Hydrogenation. In Comprehensive Chemical Kinetics; Bamford, C. H.; Tipper, C. F. H., Eds.; Elsevier: Amsterdam, 1978; Vol. 20, pp 1-121.

19. Gonçalves, L. P. L.; Wang, J.; Vinati, S.; Barborini, E.; Wei, X.-K.; Heggen, M.; Franco, M.; Sousa, J. P. S.; Petrovykh, D. Y.; Soares, O. S. G. P.; Kovnir, K.; Akola, J.; Kolen'ko, Y. V. Combined Experimental and Theoretical Study of Acetylene Semi-hydrogenation over $\mathrm{Pd} / \mathrm{Al}_{2} \mathrm{O}_{3}$. Int. J. Hydrogen Energy DOI: 10.1016/j.ijhydene.2019.04.086. Published Online: May 9, 2019.

20. Molero, H.; Bartlett, B. F.; Tysoe, W. T. The Hydrogenation of Acetylene Catalyzed by Palladium: Hydrogen Pressure Dependence. J. Catal. 1999, 181, 49-56.

21. Najafishirtari, S.; Brescia, R.; Guardia, P.; Marras, S.; Manna, L.; Colombo, M. Nanoscale Transformations of AluminaSupported $\mathrm{AuCu}$ Ordered Phase Nanocrystals and Their Activity in CO Oxidation. ACS Catal. 2015, 5, 2154-2163.

22. Denton, A. R.; Ashcroft, N. W. Vegard's Law. Phys. Rev. A 1991, 43, 3161 .

23. Osswald, J.; Kovnir, K.; Armbrüster, M.; Giedigkeit, R.; Jentoft, R. E.; Wild, U.; Grin, Y.; Schlögl, R. Palladium-gallium Intermetallic Compounds for the Selective Hydrogenation of Acetylene: Part II: Surface Characterization and Catalytic Performance. J. Catal. 2008, 258, 219-227.

24. McCue, A. J.; McRitchie, C. J.; Shepherd, A. M.; Anderson, J. A. $\mathrm{Cu} / \mathrm{Al}_{2} \mathrm{O}_{3}$ catalysts modified with $\mathrm{Pd}$ for selective acetylene hydrogenation. J. Catal. 2014, 319, 127-135.

25. Liu, X.; An, W.; Wang, Y.; Heath Turner, C.; Resasco, D. Hydrodeoxygenation of Guaiacol over Bimetallic Fe-alloyed (Ni, Pt) Surfaces: Reaction Mechanism, Transition-state Scaling Relations and Descriptor for Predicting $\mathrm{C}-\mathrm{O}$ Bond Scission Reactivity. Catal. Sci. Technol. 2018, 8, 2146-2158.

26. Xin, H.; Vojvodic, A.; Voss, J.; Nørskov, J. K.; AbildPedersen, F. Effects of $d$-band Shape on the Surface Reactivity of Transition-metal Alloys. Phys. Rev. B 2014, 89, 115114.

27. Gorzkowski, M. T.; Lewera, A. Probing the Limits of d-Band Center Theory: Electronic and Electrocatalytic Properties of PdShell-Pt-Core Nanoparticles. J. Phys. Chem. C 2015, 119, 18389-18395.

28. Fan, J.; Yu, S.; Qi, K.; Liu, C.; Zhang, L.; Zhang, H.; Cui, X.; Zheng, W. Synthesis of Ultrathin Wrinkle-free PdCu Alloy 
Nanosheets for Modulating d-band Electrons for Efficient Methanol Oxidation. J. Mater. Chem. A 2018, 6, 8531-8536.

29. Zhang, X.-F.; Wang, A.-J.; Zhang, L.; Yuan, J.; Li, Z.; Feng, J.-J. Solvothermal Synthesis of Monodisperse PtCu Dodecahedral Nanoframes with Enhanced Catalytic Activity and Durability for Hydrogen Evolution Reaction. ACS Appl. Energy Mater. 2018, 1, 5054-5061. 


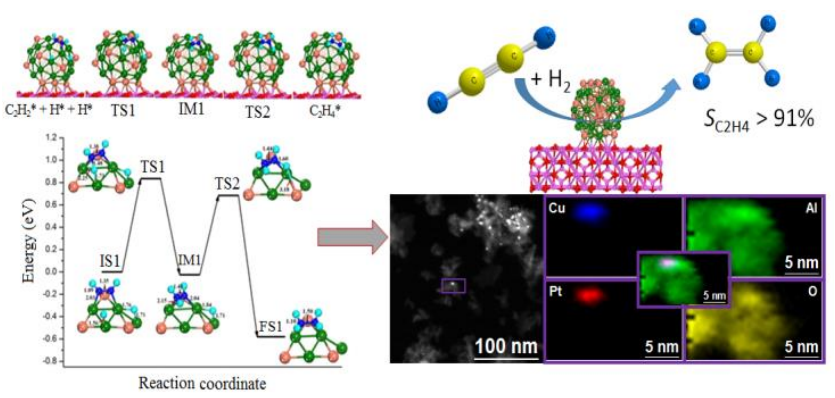

